\title{
Modified Record Base Featuring Postpalatal Seal Using Silicone Bite Registration Material
}

\author{
Won-suk Oh, DDS, MS, ${ }^{1}$ \& Berna Saglik, DDS, $\mathrm{MS}^{2}$ \\ ${ }^{1}$ Clinical Associate Professor, Department of Biologic and Materials Sciences, Division of Prosthodontics, University of Michigan School of \\ Dentistry, Ann Arbor, MI \\ ${ }^{2}$ Clinical Assistant Professor, Department of Biologic and Materials Sciences, Division of Prosthodontics, University of Michigan School of Dentistry, \\ Ann Arbor, MI
}

\author{
Keywords \\ Record base; postpalatal seal; silicone bite \\ registration material.

\section{Correspondence} \\ Won-suk Oh, Department of Biologic and \\ Materials Sciences, Division of \\ Prosthodontics, University of Michigan \\ School of Dentistry, 1011 N. University, Rm \\ K1014A, Ann Arbor, MI 48109-1078. E-mail: \\ ohws@umich.edu
}

Accepted October 7, 2010

doi: 10.1111/j.1532-849X.2011.00740.x

\begin{abstract}
This article describes a simple method of fabricating a stable and retentive record base to ensure an accurate registration of the maxillomandibular relationship. A postpalatal seal is established along the posterior end of the record base on the definitive cast using a silicone bite registration material to create a border seal along with the lip/cheek draping actions and to evaluate adequacy of the post dam.
\end{abstract}

The record base must be rigid, stable, and retentive in its intraoral position to ensure an accurate registration of the maxillomandibular relationship. ${ }^{1}$ Triad visible light-cured (VLC) resin (Dentsply International Inc, York, PA) is widely used as a record base material because it is convenient to use and free of resin monomers. ${ }^{2}$ However, the position of the record base over the edentulous maxillary arch is often unsecure because of the gaps in the tissue undercut areas and on the palate from the polymerization contraction of the resin. ${ }^{2-4}$

Methods introduced to enhance the fit and retention of the record base include staged processing, ${ }^{5}$ relining using either soft liners or silicone impression materials, ${ }^{6}$ and application of a denture adhesive underneath the record base. These methods are designed to minimize errors resulting from the dimensional change of the resin, fill the gaps underneath the record base, and adhere the record base to the oral mucosa, respectively. Common problems with these procedures, however, include inconvenience from multiple processing of the resin inside a light chamber, alteration in the positional relation because of the separation of the relining material from the record base with multiple seating and removal from the definitive cast, and difficulty of removal of the residual adhesive from the record base.

The purpose of this article is to describe a simple method of enhancing the stability and retention of the record base, using a fast-set silicone bite registration material. The definitive cast is blocked out to allow separation of the processed and rigid record base without damaging the integrity of the cast. ${ }^{1}$ A post dam is carved on the cast along the vibrating line transferred from the mouth by means of the record base. ${ }^{7}$ The base is firmly seated in position over the cast to pick up a silicone bite registration material injected along the carved post dam area and provides a border seal at its posterior end.

\section{Technique}

1. Evaluate the intraoral fit of the record base. Have the patient say "Ah" to indicate and mark the vibrating line with an indelible pencil (Color Transfer Applicator, Great Plains Dental Products Co Inc, Kingman, KS) (Fig 1).

2. Seat and secure the record base in its intraoral position with one hand. Transfer the intraoral mark to the record base by activating the soft palate using the "nose blow" method. ${ }^{7}$ Palpate the zone of tissue compression along the vibrating line with a ball burnisher (27/29, Hu-Friedy Mfg Co Inc, Chicago, IL) to indicate the area and depth of the postpalatal seal.

3. Trim the record base along the posterior end of the vibrating line with a silicone carbide abrasive (Arbor Band, Buffalo Dental Mfg Co, Syosset, NY). Seat the base over the definitive cast and mark the posterior end of the base 


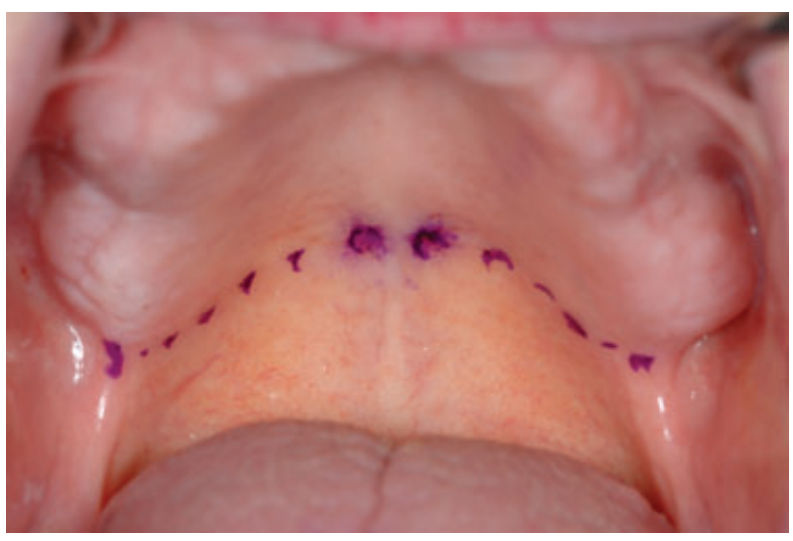

Figure 1 The vibrating line in the soft palate as indicated by an indelible pencil.

on the cast with a sharp blade (carbon steel surgical blade number 25, Miltex Inc, York, PA). Carve the post dam on the cast with a round bur (US number 8, Brasseler USA, Savannah, GA) and a wax spatula (7 Wax spatula, Hu-Friedy Mfg Co Inc, Chicago, IL) (Fig 2A).
4. Paint the tissue side of the record base along the posterior border with a silicone impression adhesive (VPS tray adhesive, Kerr Corp, Orange, CA) and coat the cast along the post dam with a thin layer of petroleum jelly (Vaseline, Unilever, Greenwich, CT). Inject a fast-set silicone bite registration material (Blu-Bite, Henry Schein Inc, Melville, NY) through a narrow lumen of dispensing tip on the cast along the post dam (Fig 2B). Seat the record base firmly over the cast in its final position. Do not disturb the setting of the silicone material (Blu-Bite) until it sets.

5. Trim the excess silicone material along the posterior end of the record base using a sharp blade (carbon steel surgical blade number 25). Lift the record base featuring a postpalatal seal to enhance the stability and retention of the record base and evaluate adequacy of the post dam (Fig 2C).

\section{Summary}

The polymerization contraction of the triad resin keeps the contact of the labial/buccal flanges of the record base against the ridge while creating a gap between the base and the palate. ${ }^{2-5}$ The breakage of the border seal, in particular at its posterior end, compromises the retention of the record base. The
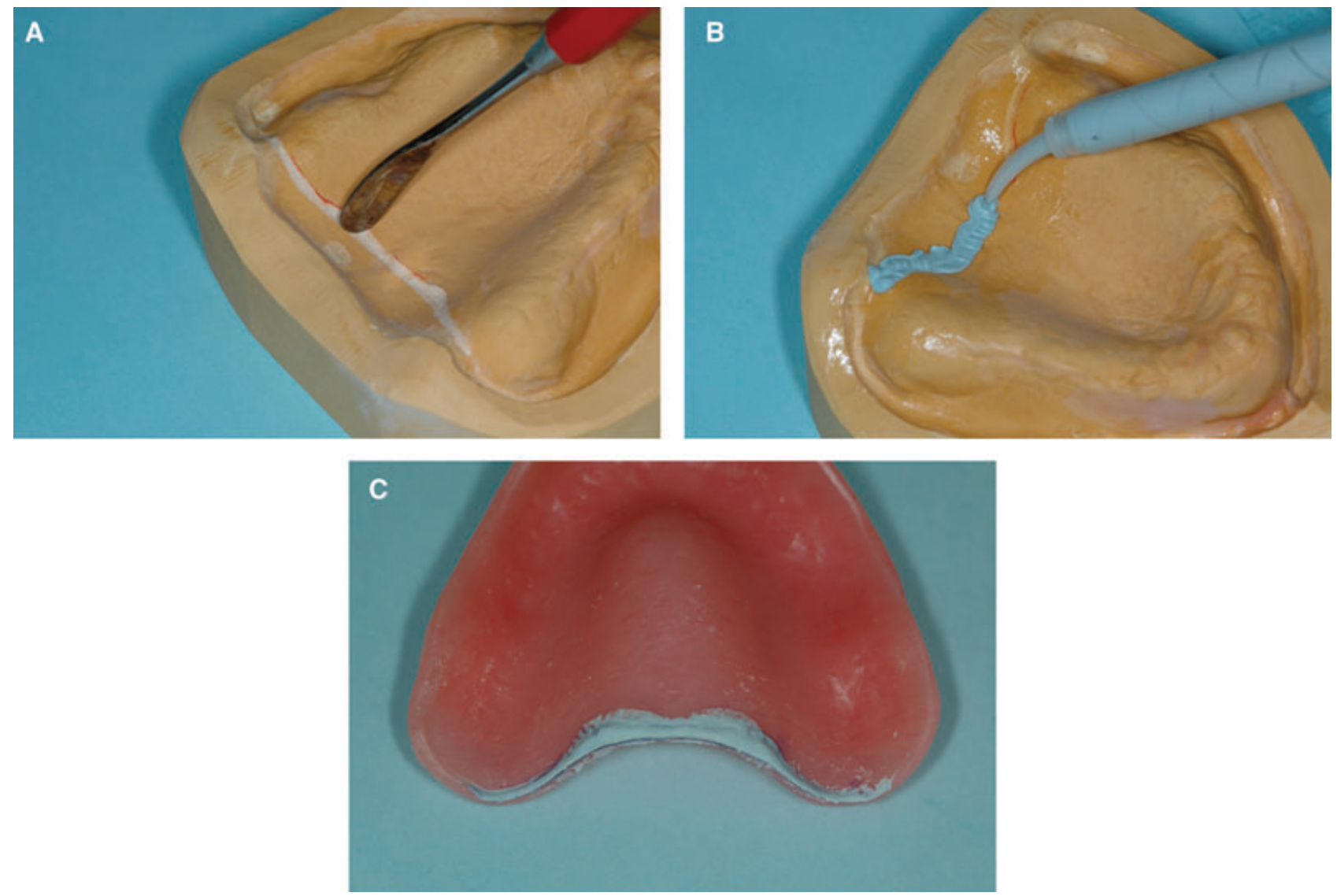

Figure 2 (A) The post dam carved on the master cast. (B) Silicone bite registration material injected on the cast along the post dam. (C) The postpalatal seal on the record base established with a silicone bite registration material. 
blockout procedure should be kept to a minimum to avoid an excessive gap formation along the vestibules so the border seal is maintained along the labial/buccal vestibules by the lip/cheek draping actions over the corresponding borders of the record base. ${ }^{6}$ However, there is no anatomic structure to aid the seal at the posterior end of the record base.

The record base itself can feature a post dam on its posterior end without using a third material when a postpalatal seal is established physiologically on a final impression. ${ }^{8}$ This technique, however, requires numerous instruments, multiple seatings of the impression in the mouth, and cooperation of the patient. The common errors with this method (insufficient and/or excessive compressions along the postpalatal seal area) may also relate to the relative rigidity or resiliency of the impression material used.

The record base is a useful device for registering the maxillomandibular relationship record and transferring the vibrating line to the definitive cast. ${ }^{7}$ A postpalatal seal formed in the record base using a silicone bite registration material features a post dam by filling the gap arising from the polymerization contraction of the resin and gently compressing the tissues along the vibrating line. This procedure is simple and performed chairside with minimum interruption between other procedures. The postpalatal seal formed by silicone material is neat and does not risk separation and subsequent positional change of the record base to the cast because of the absence of the drag of the silicone material against the cast. This modified record base ensures the maxillomandibular relation procedure is accurate and predictable and allows the practitioner to evaluate the adequacy of the postpalatal seal before intraoral evaluation of the wax denture.

\section{References}

1. Akerly WB: Recording jaw relationships in edentulous patients. Dent Clin North Am 1996;40:53-70

2. Boberick KG, McCool J: Dimensional stability of record bases fabricated from light-polymerized composite using two methods. J Prosthet Dent 1998;79:399-403

3. Tan HK, Brudvik JS, Nicholls JI, et al: Adaptation of a visible light-cured denture base material. J Prosthet Dent 1989;61:326-331

4. Sykora O, Sutow EJ: Posterior palatal seal adaptation: influence of processing technique, palate shape and immersion. J Oral Rehabil 1993;20:19-31

5. Oh W, May KB: Two-stage technique for optimum fit and stability of light-polymerized record bases. J Prosthet Dent 2008;99:410-411

6. Knight JS: Fabrication of a stable record base for severe soft tissue undercuts in the edentulous patient. J Prosthet Dent 1999;82:485-486

7. Rashedi B, Petropoulos VC: Current concepts for determining the postpalatal seal in complete dentures. J Prosthodont 2003;12:265-270

8. Ansari IH: Establishing the posterior palatal seal during the final impression stage. J Prosthet Dent 1997;78:324-326 